\title{
Communicational power of social networks: The critique of contemporary narcissism
}

\author{
Divna Vuksanović ${ }^{1}$ \\ Faculty of Dramatic Arts, University of Arts, Belgrade \\ Dedicated to my parents, Mirjana and Milentije Vuksanović
}

\section{doi:10.5937/comman1432005V}

Summary: This text draws attention to the so-called 'dark side' of the Internet and social media, with the special focus on popular network Facebook. Namely, in the time of escalation of new communication technologies, which again confirms the power of media, there is evidence that these technologies enable not only connection and instant interaction between users of network communication, but also a new form of social behavior - media constructed narcissism. This is not individual (Freud) or social narcissism (Lasch), but it is the case of completely new form of narcissistic behavior, that is illustrated using social network Facebook as example. Furthermore, judging by the research done among students in the USA, malignant narcissistic behavior (Vaknin), becomes new paradigm of 'sociablity', and, in other words, interaction. Number of friends on a certain profile verifies this sociability. Thus, this is socially constructed narcissism in cyber space, which is becoming, more and more, a trait of global culture that surrounds us.

Key words: narcissism, Internet, social networks, Facebook, culture, media

In her essay on people in dark times, Hannah Arendt notes the following: something important happened, that is, something important is happening, on a global level, between the man and his world and that something is of existential significance primarily within the public realm of human life. Due to this field of human action the world is not and can not be the same anymore. "The

\footnotetext{
1 Contact with author: divnavuk@eunet.rs.
} 
world lies between people, and this in-between - much more than (as is often thought) man or even man - is today the object of the greatest concern and the most obvious upheaval in almost all the countries of the globe" (Arendt, 1968: 12). The contemporary man is, potentially or realistically speaking, significantly in connection with the world through media. In this respect, in addition to recognizing doubtless technical advantages of new communicational media and social networks, it is necessary to reexamine 'the dark side' of various forms of communicational mediations and current processes of 'connectivity' provided by the Internet as well as popular social networks.

The communicational potential of the Internet and contemporary social networks is incomprehensible, at least from this perspective. We are witnessing an incredible expansion of new communicational technologies that are taking over the entire reality of communications, as well as the traditional understanding of the notions and praxis of 'sociability', 'politicallity', management, advertising and economics, and at last reality itself. Communication is, or appears to be, the very activity that confirms the positions of power. The will to communicate through media is becoming, as it seems, the prominent social activity today and in current times it is increasingly being expressed through interaction. The trivial assumption that the one in possession of information 'reigns' supports the fact that communicational power in contemporary times corresponds to the idea of social/political/economical domination. Mass media and even more so new media are the force of communication today. In light of these examinations, we should reconsider ways in which the Internet and new media influence global social environment, as well as the individual, i.e. the user of new communicational platforms, tools and services, with a special emphasis on a social network known as Facebook, currently the most popular and most present form of technical construction of a new idea of sociability, that is, of new symbolic values and contemporary ways of expressing narcissism.

On the one side interactivity, as a specific type of technically mediated means of communication, is increasing. On the other, in a certain way, it appears as a particular kind of reduced form of applicative filed of intersubjectivity, mostly as that which is defined through technical possibilities of modern communication media usage. Interactivity today is being used primarily as a substitute for dialogue (Virillo's (2006) 'telepresence'), while its basic technical advantage in regards to the dialogue based form of communication is the possibility to exceed spatial distance among the participants of the communicational act, as well as the speed in which it can be performed in terms of the so-called 
'real time'. As it is known, the dialogue (in the antique sense of this notion) implies immediacy and the equality of the participants, as well as the truth, that is, a search for sense - which is an indispensible, but not a sufficient precondition for the practice of this form of communication.

The paradox behind the use of Internet and new media usage, with the purpose of growth of various forms of communication appearances, lies, above all, within the gap between assumed goals of Internet communication and the end products resulting from it. When it comes to expectations, it is assumed that the Internet and social networks, such as Facebook, Twitter and others, due to their technical characteristics, amplify the possibility of communicational reaction to certain social phenomena, political circumstances, the economy of supply and demand, etc. Also, new media apparently add to the satisfaction of human cultural needs: communicational, educational, sensory (aesthetic), creative. On the other hand, looking at it from our perspective, the central point here is the switch from authentic needs to the so-called pseudo needs that are characteristic for the systematic bond between the world of capital and media. Mediation by the media is certainly not neutral in terms of values and financial interest, which directly or indirectly stands behind many network transactions, bringing into question the consequences of its overall activities.

Nevertheless, in view of this, we should also say that the mediation through communication with the new as opposed to the mass media, in a certain way, increases the level of sensitivity of the social ambience to certain phenomena, by enabling participatory communication within the widely spread cyber media sphere, currently being the discussion forum for specific problems, as well as political activism. Viral advertising, Facebook 'sharing', blogs that address a range of economic, political, media, cultural and social circumstances, forums, groups for (political) support, pressure groups and all sorts of civil activities on the Web, the preparations for various political ("the Arab spring"), cultural and other actions, and even 'hacking', are only some of the distinctive examples of communicational action typical for this media space. Connecting and networking in diverse interest based cyber communities, with no doubt supports the idea of technical expansion of communicational space, as well as the change of the dominant form of communication (in which the communication implies action, that is - interaction) in contemporary times.

On the other hand, many articles and researches about network communication activities critically address this 'sensitivity', understanding it actually as 
'insensitivity' that is being manifested as the sign of ever present narcissism ${ }^{2}$. Clearly, we are not talking here about individual narcissism - in terms of the necessary phase of human development (Freud (1914) wrote about it at the beginning of the last century), or about neurotic 'personality disorder' (Narcissistic Personality Disorder, NPD), or of specific symptomatology of contemporary times, for what Christopher Lasch (1991), Gilles Lipovetsky (1983), and many other authors gave persuasive arguments while criticizing the shallowness of the world of contemporary culture and the influence of consumer lifestyle. According to our opinion, this is something completely different. It is as if the narcissistic culture, active in the contemporary era of communication, is being transformed into its own media other, while the 'narcissism' moved to the next level of its manifestation. In this way, it became, in a certain way, the 'desirable' social value (directly linked to the attributes of market economy). Narcissism won over not only the civilization of the consuming West but, so to say, the entire global media space of today.

The so-called 'new Narcissus', ${ }^{3}$ as described by Christopher Lash (1991), is a person who, according to the imperatives of our time, neglects the past and the future; by living here and now (Hegel for instance defines this occurrence as some sort of 'nervous existence'). Internet, as a medium, as well as different social networks (such as Facebook and others), technically supports this experience, due to its very own self-definition as that of endless present tense. New media and social networks thus present some sort of transgeographical as well as transhistorical space of media action in which the dimensions of the past and future are deleted, that is, performed (synthesized) in a time dimension of now. This time reduction is enabled technically. Users' participation in cyber space is hence always already the present and done in 'real time', and confirmed through interaction - with the machine (a connected computer) or as a result of it. Extended 'sensitivity', in McLuhan's terms, does not know consciousness, due to which the participation in cyber world appears as a direct imitation of immediacy, a delusion of some sort of sensible immersion into a technologically generated new reality. This obviously sets off new shapes of 'personalization' on the one side, and 'sociability' on the other side, as well as new understanding,

\footnotetext{
Zoran Milivojević argues: "Narcissism should not be understood as the love towards oneself, but rather as the lack of sympathy when it comes to others. Narcissus, the figure from the Greek myth should be pronounced Narkis, which could be translated as the insensitive one, and it has the same root as the word narcosis" (Milivojević, 2012).

3 See the article: "Da li je narcizam čovjekovo normalno ili patološko stanje: tajna ogledala” [Is narcissism a normal or pathological human condition: The secret of the mirror], at http://www.amfiteatar.org/cgi-bin/yabb/YaBB. pl?num $=1050744437$.
} 
or else interpretation of these phenomena. To sum it up, this brings an entirely new culture of relations - the so-called cyber culture, with new narcissism as one of its trademarks.

The basic idea is that narcissism, considered as culture, is stimulated by the consumer lifestyle, as well as by mass and new media. And these are especially important to us because of their specific structures that imply users' communication in-between each other - as 'a friend' to 'a friend'. Individual narcissism defined as 'personality disorder' (as noted by Sam Vaknin in one of his videos from the series casted at YouTube) is supported by an appropriate social ambiance; the one that supports the development of the so-called malignant narcissism, and stimulates its pathological, that is, networking growth up to the limits of 'an epidemic'. Vaknin (2013) named this sort of surrounding 'the pathological space'. In interaction with a narcissistic personality it enables continuous supply for its pathology, due to the environment created for those purposes that presents the constant source of support (followers, fans, friends), which than enables the expansion of the so-called narcissistic culture on the Internet and social networks. How is this happening?

The so-called 'intelligent surrounding' presents, in fact, that 'culture' in which the interaction between individuals is performed through media. When it comes to the Internet and social networks, it seems as if they are structurally defined in such a way to enable the expansion of typical narcissistic characteristics: egocentricity, or else, one's focus on 'the self', the lack of emotional closeness/empathy, and further on, grand-mania, fantasy and magic thinking, as well as pathological addiction to the source of narcissistic supply. It is interesting that the 'common places' used to describe activities on the Internet, and especially those within Facebook, are mostly the targets of the critique of those communicational tools which are often understood in terms of personal advertising, exhibitionism, and self-promotion; since, due to the principle of a mirror and mirroring, the contemporary Narcissus confirms oneself through the interaction with another user at the Net - his/her fiction (to put it simply) becomes someone else's 'reality' and vice versa.

As an example, we will look at a research carried out at one of American universities (Western Illinois University). It was concerned with the behavior of the users on Facebook social network, and it was performed on the sample of 294 students, aged from 18 to 65 (Pearse, 2012). The results of this research, as it was published in the Guardian, show a direct connection between the number of friends created through this network and the confirmation of a narcissis- 
tic profile user - the one who shows signs of socially disruptive behavior (similar assumptions were made earlier by social media skeptics). Manifestations of 'aggressive' narcissistic behavior on Facebook are divided into two groups. Within the first one, the indicators of narcissism were considered to be: self-absorption, vanity, the feeling of superiority and exhibitionistic tendencies of a user, who through the usage of this social network pleases his/her own need to draw the attention of many of his/her Facebook friends. The other group of indicators within this research dealt with the potential filed of exploitation and manipulation, the one provided by a large group of friends made for the purpose of self promotion of that specific Facebook user (Pearse, 2012).

The key argument that followed this empirical research was based upon the fact that narcissism, thought as personality disorder, on certain social networks - in this case Facebook, correlates with the number of 'friends' of a profile user, or those he/she interacts with (liking, sharing, chatting, etc.). The large number of friends on the Network provides the user with the constant supply, due to the help of others - who are being treated as the source of stimulus. An attraction of attention offers support and satisfaction. In this way, the mutual relationship is being supported as well, the one that is being set up between the Narcissus, as an individual, and the technologically defined media ambiance that enables immediate (real time) as well as continuous satisfaction. This is provided by a large number of 'chosen' users, that is, those appropriate interactions that in technical terms support narcissistic behavior within the network, along with many friends and fans, which altogether constitutes artificially generated pathological space of manifesting friendship, and other similar forms of 'sociability'. All this presents constant supply for the narcissistic behavior of an individual within the cyber ambiance of interactivity, which is being realized as his/her sociability.

During the analysis of the malignant narcissism (opposed to the regular evolutionary phase and the healthy self esteem), Sam Vaknin (2013) emphasizes that persons with the narcissistic type of personal disorder create for, and by themselves, that exact sort of surrounding which matches their needs of continuous attention, approval, admiration and immediate emotional satisfaction. And, in the case in which the individual can create that very space within social media, the one that matches his/her own requirements, and does it by selecting those friends that fit the best his/her own narcissistic needs and tasks, this ambiance perfectly complements the future generation of pathological (aggressive) narcissism. Despite the expectations, or in other words, instead of socializing and networking that would be based on friendly connections and motivation 
to fulfill emotional closeness and empathy, what is actually going on is a distant and antisocial behavior mediated by technology, which in some cases leads to the 'psychological abuse' and psychopathic forms of behavior at the Web ${ }^{4}$.

This space enables a creation of potential narcissistic user, or else, a psychopath, since it prevents the user from the risk of emotional harm and disappointment. The virtual space provides us with the possibility of a profile opening and Web presentation through the usage of fake profiles, nicknames, virtual personas, etc. which brings along a certain level of anonymity, as well as possible irresponsibility, incorrectness and undutifulness in terms of our behavior towards the others (Vaknin, 2013). The sanctions that would follow a harassment and psychopathic behavior on the Internet and social networks are rare, and they are not being treated in an adequate way due to the permeable protective mechanisms that simulate a minimum of ethics within the cyber world. Apart from the legislation applied to pornography, occasional investigations and organized international actions directed towards the problems of online pedophilia, or criminal activities such as serious robberies of financial embezzlements, the punishments are most often symbolic ones. In the case of Facebook, they are being reinforced as 'warnings' given by administrators, and in most extreme cases they lead to the closure of the user's profile. However, that same person can open a new one, under a different, fake name and identity, and thus continue to act within the Web. In the absence of a more visible form of online censorship, when it comes to popular social networks - although security services have the possibility to follow users' activities - narcissism, as the most common and visible form of cyber behavior continues to grow.

Moreover, Sam Vaknin argues that the virtual space, which structurally supports the assumed equality of the users, presents some new sort of a proving ground for the development of narcissism. It does so by sucking into its structure those individuals who suffer from the NPD syndrome, as well as their 'victims' that later on, as he claims, take over the identical model of 'malignant' online behaviour (Vaknin, 2013). The addiction, in terms of continuous attraction of attention of many friends and web users, supports the expansion of narcissistic behavior (from the individuals to those users who support him/her

„To the narcissist, the Internet is an alluring and irrestible combination of playground and hunting grounds, the gathering place of numerous potential Sources of Narcissistic Supply, a world where false identities are the norm and mind games the bon ton. And it is beyond the reach of the law, the pale of social norms, the strictures of civilized conduct. The somatic finds cyber-sex and cyber-relationships aplenty. The cerebral claims false accomplishments, fake skills, erudition and talents. Both, if minimally communicative, end up at the instantly gratifying epicenter of a cult of fans, followers, stalkers, erotomaniacs, denigrators, and plain nuts. The constant attention and attendant quasi-celebrity feed and sustain their grandiose fantasies and inflated self-image" (Vaknin, 2013). 
in a 'friendly' way), which then becomes one of the main features of how social networks function. In other words, it seems as if the Internet, Facebook, Twitter, My Space, and other social networks multiply individual forms of narcissist behavior, by bringing it into the level of social pathology of the web behavior.

In this way, we are finally reaching apparently paradoxical conclusion that the Internet and social networks, in respect to the technical as well as the factbased point of view, on the one side support the 'social construct' of narcissism, which is most effectively represented by the social ('friendly') global network with the largest number of users today - Facebook; and on the other, its mass media application within the ungraspable cyber space. In that way, the 'narcissistic culture' of the present consumer society receives the technical support for its growth and development and moves to the next media level of realization of its own dialectic moments, while the existing infrastructure of the Net and social networks foster this process. Hence, the so-called 'global culture' becomes and remains narcissistic, and does that not only within the sphere of action of the consumer society's political economy, but also within the symbolic ambiance of new media that is evidently becoming its equivalent, and which is made of the Internet, social networks and the entire space of realization of the so-called 'cyber culture'. This widely spread phenomenon of an individual as well as socially constructed narcissism within the framework of the cyber space should attract our attention, initiate research, and thus lead to a thorough questioning of concepts of (inert)activity and 'sociability', which are often being used affirmatively, that is, uncritically within the contemporary media theory/ philosophy and practice. 


\section{References}

Arendt, H. (1968). On Humanity in Dark Times. In H. Arendt, Men in Dark Times. London: Penguin Books.

Freud, S. (1914). On Narcissism: An Introduction. In Standard Edition of the Complete Psychological Works of Sigmund Freud. London: Hogarth Press.

Lasch, C. (1991). The Culture of Narcissism: American Life in an Age of Diminishing Expectations. New York: Norton.

Lipovetsky, G. (1983). L'ère du vide: Essais sur l'individualisme contemporain. Paris: Gallimard.

Milivojević, Z. (2012, August 3). Novi muškarac. Politika.

Pearse, D. (2012, March 17). Facebook's 'dark side': Study finds link to socially aggressive narcissism”. Guardian. Retrieved from: www.guardian.co.uk/technology/2012/mar/facebook-dark-side-study-aggressivenarcissism?CMP=twt_gu.

Vaknin, S., (2013). Cyber (Internet) Narcissist and Psyhopaths. In S. Vaknin, Malignant Self Love: Narcissism Revisited. Retrieved from: www.narcissisticabuse.com/journal67.html. 